\title{
Assessing Factors Affecting the Patronage of Health Insurance Schemes: An Evidence of Ghana
}

\author{
Dai Baozhen (Corresponding author) \\ Jiangsu University, School of Management, Xuefu Road, 212013, \\ Zhenjiang, P.R. China \\ E-mail: hixiaodai@126.com
}

Minkah Andrews Yaw

Jiangsu University, School of Management, Xuefu Road, 212013,

Zhenjiang, P.R. China

E-mail: nanayawminks@gmail.com

Osei-Assibey Mandella Bonsu

Jiangsu University, School of Finance and Economics, Xuefu Road, 212013,

Zhenjiang, P.R. China

E-mail: thugdibae1@gmail.com

Agyemang Fredua Sylvester Prempeh

Jiangsu University, School of Management, Xuefu Road, 212013,

Zhenjiang, P.R. China

E-mail: prempehfredua@gmail.com

Received: Dec. 9, 2018 Accepted: Feb. 23, 2018 Online published: Mar. 1, 2019 doi:10.5296/jpag.v9i1.14442

URL: https://doi.org/10.5296/jpag.v9i1.14442 


\section{Abstract}

The Ghana Health Insurance Scheme was established to ensure enhancement in the quality of rudimentary health care services to all citizens. Notwithstanding the seemingly splendid financing structure, yet, there is empirical evidence of low enrolment. The study investigated the factors that have accounted for the truncated patronage of the health insurance scheme in Ghana. It also seeks to ascertain the factors that motivate individuals to join the scheme and finally examine the challenges of the scheme coverage expansion. The study used both interview, primary, and secondary data. The cross-sectional model was used to investigate the factors effects on NHIS. It was revealed that Income level, family characteristics, risk perception, and health care system delivery has an imperative negative influence on the low enrolment of the NHIS scheme in Ghana. However, questionnaires and interviews were used to find out from respondents and clients on the motivations and challenges associated with the scheme. The findings revealed that majority of the respondents agreed that access to free drugs is the strong arsenal that motivates individuals reluctant joining the scheme. The study further revealed that, majority of the respondents representing $87 \%$ have the notion that, negative attitude of the service providers at the health centers was the main barrier of the scheme among subscribers and non- subscribers in Ghana. Our results have practical implication that, intensive education should be enrolled out by the National Health Insurance Authority (NHIA) to change the negative perception of people in relation to the challenges among both subscribers and non-subscribers.

Keywords: health insurance, subscribers, enrolment, schemes, Ghana

\section{Introduction}

In the light of the Millennium Development Goal target for health improvements and reduction of poverty, there was a growing impulse towards providing worldwide coverage health services, implying that the populace across the globe has access to suitable health care when desired at affordable cost. One imperative measure to upsurge affordability is to bring down the out-of-pocket payment which users make for health care. Many low- and middle - income countries rely heavily on patients' out-of-pocket health payment to finance their health care systems (Xu, et al., 2007). According to the World Health Organization (2000), out-of-pocket health payment is the least efficient and the most inequitable means of financing health care. It prevents people from seeking medical care and thus, exacerbating poverty. These are widely recognized barrier to accessing healthcare, especially in poorer countries and thus pushing household further into poverty. Social health insurance is seen as one of the health financing approaches with a strong potential to share risks across the population and time. As the membership of social health insurance is mandatory, it avoids many of the problems of adverse selection which smaller, voluntary health care schemes face.

In the past few days, there were few large-scale social health insurance schemes running in Sub-Saharan Africa. Over the past decade, however, experiments in social health insurance have been vault up in a number of African countries such as Ghana, Nigeria, Rwanda, Kenya and Tanzania (Carrin, et al.2008; Witter and Garshong, 2009; Mensah, et al. 2010). 
Ghana has prioritized universal coverage, regarded as 'access to satisfactory healthcare at all at affordable cost', of health care services and has hence set up approaches and projects to meet this objective. Various health financing changes have been executed, gone for expanding by and large resources to the health sectors, and divisions thus, guaranteeing evenhanded portion, the current of which is the National Health Insurance Scheme (NHIS), to upgrade social health protection. Preceding the foundation of the NHIS in 2003, Ghana actualized the greater part of the known healthcare financing components including general duty tax and donor funding, out-of-pocket payments, and community-based medical coverage plans. (Freeman and Zhang, 2011). To pad the weight of out-of-pocket for medical services, the government of Ghana, inducted an exceptions strategy focused at children younger than 5, pre-natal consideration for pregnant women, the penniless and poor people, the older, and for and for some disease-specific services (Government of Ghana/SAPRI 2001; Singleton, 2006). In spite of having a comprehensive policy, there was extensive proof that the exclusion approach was ineffectively supported and actualized as the same number of the individuals who ought to have been exempted did not get them (Nyonator and Kutzin, 1999) referred to in(Geng, Janssens et al. 2018). The populace, in this manner, had decreased access to hospital services and, thus negatively affected hospitals financial performances. (Atim and Sock, 2000). The troubles in bearing the expense of hospital bills incited mission clinics to present insurance schemes managed together by the society and the health center as a procedure to keep away from the issues related with paying for services at the point of consideration. In the year 2003, there were 168 smaller Mutual Health Organizations covering about $1 \%$ of the populace leaving numerous Ghanaians defenseless in case of calamitous sickness. (Atim, et al., 2001; Sulzbach, et al., 2005). In order to expel the financial hindrances to getting to health care services and to guarantee impartial circulation of value benefit particularly to poor people and vulnerable, the government of Ghana introduced the National Health Insurance Scheme in the country. The National Health Insurance Scheme Act (Act 650) was accepted into law in Ghana in the year 2003, though implementation in terms of benefit began in 2005 .

The introduction of the NHIS was to make healthcare services accessible, affordable, available and acceptable by all domiciled Ghanaians. The National Health Insurance Scheme was acquainted all together to get rid of the "cash and carry system in the Ghanaian society". Under that framework, the health needs of an individual were just taken care of after initial payment for the services was made. Indeed, even in situations where patients had been brought into the health centre on emergency, it was necessitated that cash was paid at each purpose of service delivery. Since the establishment of Ghana National Health Insurance Scheme (NHIS) in 2003, Ghana as a country has gained considerable ground toward its objective of universal health care. In the year 2009, the NHIS secured 10.5 million individuals or 40 percent of Ghana's populace. The complete number of inpatient and outpatient visits to health facilities ascended from a margin of 0.5 to 1.5 for each per capita in 2009 (NHIS, Ghana Annual Report 2009). The National Health Insurance Scheme has been acknowledged by Ghanaians as a standout amongst the best social interventions projects to be inducted in the country. Different explores have uncovered that the National Health Insurance Scheme has extended access to health care for most of the populace who until now couldn't bear health care under the 'cash and carry ' system. Additionally, the NHIS was to guarantee 
improvement in the nature of fundamental health care services for all indigenes, particularly poor people and vulnerable. Following quite a while of being stacked under the cash and carry system, the enlistment of the NHIS has gotten noisy commendation particularly among the poor who currently locate a social insurance system that gave aid to their health care spending issues. (Adamba, 2010). Notwithstanding this seemingly splendid financing structure, there is empirical evidence of low enrolment, but there exist deficiency of information in the logical reasons, particularly regarding how poor people and low wage bunches who are the principal target population for accomplishing the quality in the health care system have profited from the scheme. Just $36 \%$ of the populace are covered following a time of the scheme introduction (Oxfam 2013) suggesting the universal health coverage status has not yet been achieved. Therefore, the study seeks to examine the factors that have accounted for the low patronage of the scheme. It also seeks to ascertain the factors that motivate individuals to join the scheme and finally, examine the challenges of the scheme coverage expansion. However, the study focused on the factors for low patronage regarding its significance since the scheme is said to be non-profit in nature, an option seen as having the potential for attracting large membership.

The rest of the paper is as follows. The next section reviews past research addressing health insurance scheme. The third section gives the methodology of the study. The fourth section analyzes the results and the last section concludes the study

\section{Literature Review}

\section{Concepts of Health Insurance}

Definition of Health Insurance.

Arhin-Tenkorang (2001) defined, health insurance as a mechanism characterized as a component in which the dangers of causing health care costs are spread over a gathering of people or households. The term health insurance is essentially used to portray that type of insurance which pays for practically all medical costs. It is ordinarily utilized substantially more comprehensively to incorporate protection covering long haul nursing and disability care needs. (Quaye, 1991 as cited in (Singh and Kumar 2017) .It might be given through a private insurance company, organization, or from a government supported social insurance program. On this premise, health insurance is one that is against the danger of causing medical costs among people. By approximating the general danger of social insurance and wellbeing framework costs among a specific gathering of people, a safety net provider can build up a normal fund system, for example, monthly premium or payroll tax to guarantee that, cash is accessible to pay for the medicinal services of the group as stipulated in the health care coverage assertion.

\section{Health Insurance in Ghana.}

Under the colonial rule, Ghana like numerous other Africa nations, sorted out its health systems basically to profit a little tip top gathering of colonials and their specialists (Arhin-Tenkorang, 2001). Health care arrangement happened mostly through clinics in urban territories, with direct payment at the purpose of utilization. Whatever is left of the populace 
depended on services from a scope of suppliers, for example, traditional healers and missionary health centers. After Ghana's independence, the government of Ghana provided medical care free to the populace at public health centers. Health care was financed by general taxes and other donor aid, client charges were expelled and consideration was coordinated at building up a wide scope of essential health care facilities across the nation. (Arhin-Tenkorang, 2001). By the mid-1970s, general tax income in Ghana, with its stagnating economy, couldn't augment a tax based health financing system. In the health sector, there were deficiencies of fundamental medications, supplies and equipment, and low quality of care. In 1985 Ghana started health sector changes as a major aspect of more extensive basic modification programs pointed for the most part at diminishing government spending to address budgetary shortages, presenting cost recuperation instruments through client expenses and changing wellbeing administrations to permit private sector involvement. The financial points of the reform were accomplished and deficiencies essential medications and supplies accepted. However, these accomplishments were looked by disparities in financial access to basic clinical services (Waddington and Enyimayew, 1990) as cited in (Mebratie, Sparrow et al. 2015). In 2003, the NHIS was passed into law and under the law; there was the establishment of National Health Insurance Authority (NHIA). The NHIA was to permit, monitor and regulate the activities of Health Insurance Schemes in Ghana. In the same way as other nations in the world, Ghana's Health Insurance was formed out to meet the particular needs of its citizens. (Act of Parliament; Act 650). The NHIS is financed through a central National Health Insurance Fund (NHIF) which is sourced from the National Health Insurance Levy (NHIL) of $2.5 \%$ duty on selected products and services; $2.5 \%$ of Social Security and National Insurance Trust (SSNIT) demands, generally by formal area specialists; payment of premiums, and donor fund. People who are employed in the formal sector and contribute to SSNIT are exempted from premium payment. From the year 2012, over $70 \%$ of the NHIS budgetary inflows originated from the NHIL; $17.4 \%$ from SSNIT commitments and $4.5 \%$ from premium payments. Different sources of financing to the NHIS incorporate cash designated by the parliament of Ghana, stipends, gifts, endowments/intentional commitments, and premiums accumulated from the investment.

\subsection{Types of Health Insurance in Ghana}

Ghana's National Health Insurance Scheme (NHIS) is a fusion of the traditional Social Health Insurance and Mutual Health Insurance and directed marginally via a district-wide Mutual Health Insurance Schemes with a vital system at the nationwide level to amass formal sector aids. The health insurance law 2003 (Act 650) allows for the establishment and operation of the three types of health insurance schemes in Ghana namely: District Mutual Health Insurance schemes (DMHIS), Private Commercial Health Insurance Schemes (PCHIS) and Private Mutual Health Insurance Schemes (PMHIS). (Government of Ghana, 2003).

\subsection{The Empirical Literature on Factors Affecting the Patronage of Health Insurance}

Numerous studies have been conducted in recent years on the patronage of health insurance. Sulzbach, et al. (2005) conducted a study that revealed that household head characteristics (older age, female gender, higher education, and employment) envisage insurance patronage 
at the household level, whereas these factors plus household wealth augmented the likelihood of enrolment at the individual level. With regards to participation in health insurance, those who are susceptible to illness were more likely to participate than their counterparts.

Of course, persons who are educated and those who are prone to disease are more likely to patronize health insurance schemes than their counterparts because they have fairer understanding and experience of the scheme to be able to associate with the benefits.

Jehu-Appiah C., et al noted that discernments related to provider schemes and public attributes play a significant role, although there was a varying distinction in household decision to voluntarily enrol and remain enrolled in health insurance schemes. Policy makers need to embrace household taught as potential obstacles or enablers to enrolment and invest in understanding them in their design of interventions to stimulate enrolment. With a household survey of 3301 and 13865 individuals, the study results demonstrate that Health scheme factors have the most grounded relationship with willful enrolment and maintenance choices in the NHIS. In particular, these identify with advantages, accommodation and cost of NHIS. In the meantime, while household had positive perceptions with respect to specialized nature of consideration, advantages of NHIS, the comfort of NHIS organization, and had suitable network convictions and frames of mind, they were negative about the cost of NHIS, supplier dispositions, and peer pressure. The uninsured were more negative than the insured about benefits, convenience, and cost of NHIS. If indeed household and individual perception about schemes do affect enrolment and retention in the scheme, then NHIA must invest in education and awareness creation in order to maintain positive perceptions about the scheme. However, customer perception is just one of the many factors that combine to affect patronage positively or negatively. Again, it stands to reason that those who are insured are more positive about the benefits than those who are not because it is that positivity that influences their decision to register and subsequently renew their membership and vice versa.

Again, Varatharagan Durairaj, et al, (2010) noted that where the scheme focused vigorously on addressing the necessities of poor people and giving health insurance protection on the standards of value, solidarity, hazard sharing, cross-appropriation, reinsurance, customer and community relationship, esteem for cash, good governance, and transparency in the health care delivery, NHIS inclusion is in this manner most noteworthy in the most burdened region and district, where there is a higher rate of poverty, bring down dimensions of female proficiency and lesser health care facilities and where the needs of the pregnant women and the old may not be met.

While some research may predict higher patronage and participation for people with higher income, there is no doubt that that is associated more with those working in the formal sector and live in the urban areas. As Varatharagan, et al, 2010, stated, poorer people in the rural setting who understand the benefits of health insurance are dependent on these schemes for health services just because they may not be able to pay for their services when they need it most. However, the influence that knowledge about the scheme has on patronage in the rural communities cannot be overemphasized. Hence, even though patronage may be higher in a rural setting it is dependent more on the knowledge and understanding that rural people have 
other than the factors noted above by Varatharagan and others.

James Kimani, et al, (2012), carried a study and it was revealed that being employed in the formal sector was importantly associated with a higher probability of having public health insurance according to multivariate analysis relative to employed in the informal sector.

Income was a noteworthy indicator of health insurance ownership. In particular, respondents in poor category were fundamentally more averse to be individuals from health insurance to those in the non-poor classification. In the unadjusted regression analysis, women were more averse to have been enlisted in health insurance contrasted with men. However, in the adjusted regression analysis, they were bound to have taken an interest in the program. Marital status was additionally a critical indicator of having a medical coverage program. Respondents who were in the past in an association and the individuals who were never in an association were less inclined to take part in health insurance contrasted with the individuals who were right now in an association. In the wake of controlling other puzzling components, age, education, and living residence of respondents were related with support in the health insurance scheme. Moreover, an exploration conducted by Alan and Jessica (2006), uncovered that reasonableness of inclusion is probably going to be a factor in enrolment decisions as people and families with incomes under multiple times the government poverty line, and is more averse to enroll than those with high family revenues. Descriptive tabulations of this research paper uncovered that grown-ups with frail or dubious inclinations for inclusion are bound to be uninsured than those revealing solid preferences. This report additionally uncovered that solitary workers and wedded couples with feeble or uncertain preferences are more averse to get occupations with health insurance than those with solid preferences. Affordability also has all the earmarks of being an obstacle to enrollment as the individuals who are poor or near poor, low, or middle income are less likely to enlist than single specialists with high livelihoods. This research work at long last demonstrated that school graduates or those with some school training are bound to enroll than those with less education. Grossman (1972) as cited in (He and Nolen 2018), likewise detailed a critical positive connection among income and education on health care demand. For the most part, higher salary diminishes the opportunity cost related with the acquisition of medical coverage. In this manner increments in both income and education are relied upon to build the likelihood of buying of health insurance. The impacts of demographic and financial factors, for example, age, marital status, business and employment and gender on health insurance have been variously studied.

Grossman and fellow researchers, Alan and Jessica (2006) have common findings which demonstrate income and affordability as a factor that influences patronage. But this applies more to voluntary and privately run insurance schemes as against government insurance schemes. In that case, the annual premiums become an impediment to enrolment. Those informal sectors where these types of schemes are rolled out as part of their employment package or working conditions are more likely to enroll.

Couples respondents are more probable to take insurance coverage (Trujillo, 2003; Liu and Chen, 2002) and those employed are also more likely to undertake coverage (Butler, 1999 as 
cited in (Saltzman 2018), Savage and Wright, 1999 as cited in (Ratner, Zendjidjian et al. 2018).

Harmon and Nolan in 2001 indicated that marital status had a meaningfully positive effect on the demand for health insurance. In Ghana's NHIS, children under-18 years, whose parents or guardians pay their own contributions, are exempted from paying any involvement. Thus married couples may demand insurance in order to guard their children and also tend to be more averse to the risk of shocking health expenses. From the above, it is conclusive that this study is enriched with challenges facing people in accessing National Health Insurance as well as the variables that influence patronage in a health insurance scheme. However, most of these researches focused on privately run insurance schemes as against government-run insurance schemes. More often than not, government-run insurance schemes are affordable and are targeted at the poor. Therefore, if most research indicates a positive relationship between income and enrollment, then it can be assumed that they are applicable to areas where the premiums are high and are targeted at those who can afford such schemes. In Ghana where the main insurance scheme is government-run, this seems to be the opposite.

Research has shown that those in lower economic quintile patronize health insurance more because they are vulnerable. Again, the NHIS in Ghana covers very basic and simple health conditions which the poor are vulnerable to. A lot of people have complained about service delivery in the NHIS as compared to paying cash for health care. Evidence abounds that, persons who pay cash at service delivery points are attended to earlier and treated well as against those on insurance schemes. As a result, those who have options (the rich) prefer to pay for their health services as against using health insurance cards.

However, it is true that marital status influences enrolment but there are still different reasons why this is so. This is because, with the government-run insurance scheme, married people once insured have covered all their children below 18 years. As a result, people see it as economically prudent and advantageous to enroll in a scheme that caters for their children while paying a relatively cheaper premium. That notwithstanding, couples with large family sizes are naturally more likely to get insurance because of the family size. As is expected, the risk associated with getting insurance for a large family is lower than having to pay cash at all service delivery centers once any member encounters a health complication.

This research, therefore, seeks to fill the gap associated with patronage of government-run Health insurance scheme which is expected to be affordable and reliable.

\section{Methodology}

\subsection{Research Design}

The study employed descriptive and exploratory research designs. These research designs were used to collect and analyzed data which assisted in establishing the correlations between the variables. The research also adopted a quantitative method of research to offer a description of the health insurances scheme and factors that affect the patronage of NHIS in Ghana. 


\subsection{Population and Sample Size}

2019, Vol. 9, No. 1

The population of the study consists of five districts assemblies in Ashanti Region under the Ghana health insurance scheme. The study employed a random sampling of Ghana health insurance scheme on the various Ghanaian Health Facilities. In this, clients were randomly selected from each district assembly in Ghana from the period of 2015 -2018 to match the secondary data for the analysis. The names of the selected districts are displayed in the appendix.

\subsection{Data Collection Procedures}

The study utilized questionnaires to collect primary data from respondents to gather information on the factors affecting the low patronage of the scheme and the perceptions of factors that motivate individuals to join the scheme and the challenges of the scheme coverage expansion. The secondary data were obtained from Ghana Health Insurance Authority and Ministry of Health on health indicators, enrollment to the scheme from 2015-2018. The questionnaires on the study were tested before it was deployed to ensure readability and effectiveness (Idolor, 2010). With this, experts from Health Insurance Authority assessed the questionnaires for worth assurance of the purposes of the study, therefore extraneous items were dismissed before it was deployed. The questionnaires were made up of four sections. The first part dealt with the profile of the respondents. The second section addressed the reasons that have accounted for the low patronage of the Ghana Health Insurance Scheme. The third section focused on the factors that motivate clients to be enrolled on the scheme and the last section captured the problems associated with the coverage expansion of the scheme. It is worth noting that some of the statements in the last section were used from the past studies. The sections of the questionnaires were anchored using the Likert type of scale from five (5) Strongly Agree to one (1) strongly disagree. This helped to prevent biased responses. However, clients were randomly interviewed on the challenges that are associated with the patronage of the national health insurance scheme.

However, Cronbach Alpha assist in evaluating the reliability of the questionnaires. Therefore, the primary data of this study helps to ascertain the consistency of the model used. The reliability coefficients have to be more than or equal to 0.7 of the Cronbach's consistency for reliability to be acceptable. (Cooper \& Schindler, 2008).

Table (I). Reliability of Coefficient of the study Variables

\begin{tabular}{c|c}
\hline Scale Factor & Cronbach's Alpha Coefficient \\
\hline Income Level & 0.813 \\
\hline Family Characteristics & 0.725 \\
\hline Risk Perception & 0.825 \\
\hline Scheme Characteristics & 0.723 \\
\hline Health Care Delivery Characteristics & 0.817 \\
\hline
\end{tabular}

As depicted above, it is obvious that all variables have coefficients more or equals to 0.7 . With this, they befit the data specification. The National health insurance Scheme was extracted from the National Health Authority of the five districts Assemblies registered on the scheme from the period of 2015-2018. Thus, the data serves as a secondary data for this 
paper.

\subsection{Model Specifications}

The study used multiple regression model in finding the factors that affect the low patronage of health insurance scheme in Ghana and is given by:

$$
\begin{aligned}
& \beta_{0}+\beta_{1} \text { incomelevel }_{1}+\beta_{2} \text { family characteristics }_{2}+ \\
\text { HIS }= & \beta_{3} \text { Risk perception }_{3}+\beta_{4} \text { scheme characteristics }_{4}+ \\
& \beta_{5} \text { healthCRDEsyscharacteristic }_{5}+\varepsilon_{t}
\end{aligned}
$$

Where HIS= Health Insurance Scheme as at 2015-2018, Family characteristics includes: size, age, composition, gender, education level, knowledge of insurance and solidarity level; Risk Perception level consists of Perceived health status, Beliefs on risk causation and Health-seeking behavior. Scheme Characteristics consists of benefits package, premium rate, Payment modalities, and Out-of-pocket use price and health care characteristics.

The dependent variable for the study is the Health Insurance Scheme. The independent variables are embodied by the factors that affect the patronage of the scheme: Income Characteristics, Family characteristics, Risk perception, scheme characteristics, and health care delivery characteristics. They represented the decisions that they pose on the enrolment of the scheme. Respondents were asked about the factors for the low enrolment on the scheme using the Likert Scale ranges from (1) strongly disagree to strongly agree (7). The results from the respondent (Income Characteristics, Family characteristics, Risk perception, scheme characteristics, and health care delivery characteristics) obtained are included in the model by finding the arithmetic mean used. Since, it is easy to compute. However, with two or more variables, they roughly provide the use of the arithmetic mean to arrive at the average.

\section{Data Presentation, Analysis and Discussion}

\subsection{Descriptive Analysis}

The descriptive analysis presents and discusses the data obtained from the structured questionnaires. Sixty (60) respondents were contacted from the five district assemblies sampled in the Ashanti Region of Ghana, with six respondents from each district. Out of the 60 respondents, 55 respondents representing 95 percent participated in the study were Managers, Client officers, accounts officer, secretaries, relationship managers, and customer care. Fifty-Eighty percent of the respondents had at least five working experience. Summary of these findings are shown below in Table II 


\section{Macrothink}

Table (II). Shows Respondent Profile

\begin{tabular}{llll}
\hline Description & & Frequency & Percentages \\
\hline Gender & Male & 37 & 61.67 \\
Age & Female & 23 & 38.33 \\
& <25 years & 15 & 25 \\
& 26-34years & 14 & 23.3 \\
35-40years & 21 & 35 \\
Education & 40yearsand Above & 10 & 16.66 \\
Qualification & & & \\
& Diploma & 35 & 58.3 \\
Years of Experience & Bachelor's Degree & 20 & 33.3 \\
& Master's Degree & 5 & 8.4 \\
& 6-10 Years & 35 & 58.3 \\
& 11 and Above Years & 5 & 33.3 \\
\hline
\end{tabular}

\section{a. Factors that Motivate People to join the Scheme}

With the questionnaires deployed to the targeted respondents: Client Officers, Accounts Managers, secretaries, relationship managers, and customer care were asked to indicate the factors that motivate people to join the Scheme with Likert Scale type from (1) Strongly Disagree to (2) Strongly Agree.

Table (III). Shows Factors that Motivate People to Join the Scheme

\begin{tabular}{|c|c|c|c|}
\hline Motivational Factors & Frequency & Mean & $\begin{array}{l}\text { Std. } \\
\text { Devn. }\end{array}$ \\
\hline Affordable health insurance premium & $81 \%$ & $5.65(3)$ & 0.0121 \\
\hline Access to free drugs & $91 \%$ & $5.81(1)$ & 0.072 \\
\hline $\begin{array}{l}\text { social security against unforeseen health } \\
\text { problems }\end{array}$ & $89 \%$ & $5.7(2)$ & 0.025 \\
\hline $\begin{array}{l}\text { Encouragement by friends, family } \\
\text { members, and Colleagues }\end{array}$ & $79 \%$ & $5.25(4)$ & 0.084 \\
\hline
\end{tabular}

From the table (III) depicted above, respondents agreed that all the factors stated above motivate people to join the National Health Insurance Scheme. However, majority of the respondents agreed that access to free drugs is the strong arsenal that motivates people to join the scheme. It had a mean rating of (5.81) representing $91 \%$. Another factor according to the respondents was that, social security against unforeseen health which accounted for a mean rating of (5.7) representing $89 \%$. The respondents supported their argument with the fact that, sickness emerges at any time and would not inform when and where it will incept. Therefore, with the National Health Insurance Scheme (NHIS), individuals would not be agitated since insurance is there for assistance.

They further agreed that the affordable health insurance premium is a major factor that motivates people to join the scheme with a mean rating of (5.65) representing $81 \%$. At times, individuals find it tedious to get money for health care, when this happens, since the NHIS subscriber has contributed something little as premium, the victim would be able to visit the hospital. The least of the factors according to the respondents that motivates people to join 
the Scheme is an encouragement by friends, family members and colleagues. It had a mean rating of (5.25) with a percentage of $79 \%$.

However, Respondents was asked about their perception of the challenges or barriers associated with the patronage of National Health Insurance in the selected districts. The table (IV) below shows the summary of their views:

\section{b. Challenges to Health Insurance Scheme}

Table (IV). Barriers to Health Insurance Scheme

\begin{tabular}{|c|c|c|c|}
\hline Barriers to Health Insurance Scheme & Percentage & Mean & $\begin{array}{l}\text { Std. } \\
\text { Devn }\end{array}$ \\
\hline Long queues and Waiting time & $77 \%$ & $4.95(3)$ & 0.196 \\
\hline $\begin{array}{l}\text { Perceived poor quality of drugs } \\
\text { negative attitude of the service providers at the health }\end{array}$ & $71 \%$ & $4.53(2)$ & 0.32 \\
\hline $\begin{array}{l}\text { hospitals } \\
\text { negative attitude of the service providers at health }\end{array}$ & $87 \%$ & $5.51(1)$ & 0.193 \\
\hline insurance offices & $69 \%$ & $3.9(4)$ & 0.24 \\
\hline
\end{tabular}

From the above table (IV), empirically, majority of the participants agreed that negative attitude of the service providers at the health centers was identified as a major barrier among both subscriber and non- subscribers in Ghana. It is followed by perceived poor quality of drugs (4.53) representing a percentage of $71 \%$. The next barrier associated with health insurance according to the respondents is long queues and waiting time for registration with a mean rating of (4.95) representing a percentage of $77 \%$. The least of the challenges associated with health insurance subscription according to respondents was the negative attitude of the service providers at the health insurance offices.

Therefore, sections of clients were randomly selected to be interviewed to share their experiences on the barriers associated with the patronage of National Health Insurance as discussed on the table (IV).The following quotes outline the shared experiences of the subscribers in this regard. In regards to the "quality of poor drugs". This is what both subscribers and non-subscribers shared.

The nature of the medications I was handed the last time I went to the health center was bad by any means. They (drug specialists) just give you paracetamol and there's nothing more to it. At that point, they'll request that you go and purchase the rest somewhere else, despite the fact that they realize paracetamol would not fix your infection. They just disclosed to me that NHIS doesn't cover whatever is left of the medications and requested that I go and purchase normal nutrient $C$ and that NHIS doesn't cover it. Subscriber, Male, 28 years.

Non Subscriber shared his experience as; I went to a private hospital. I was asked whether I had subscribed to NHIS and my response was no, but the treatment they gave me was superb and terrific and they gave me good drugs as well. The drugs really worked well for my sickness amicably when I took them. This shows that, if I were to be NHIS scheme holder, the drugs they would have provided to, hmm, would have been something to write home about. - 
Non - subscriber, Male, 26 years.

In regards to "Negative attitude of the service providers at the health centers. A Subscriber interviewed said that the attitude of healthcare providers is particularly on the nurses. This is the summary;

For the attitude of nurses, I feel not to talk about it. Some of them perceive that they are better than anybody else. They feel reluctant to answer you as a client who deserve to be listened to. I have had an experience of which a nurse insulted me. - Subscriber, Female, 29 years.

The last I went to the hospital, the nurses didn't do anything negatives towards me even though they are perceived to be recalcitrant. The individuals who gave my medications to me (drug specialists) likewise didn't do anything terrible to me or offended me. I was just in the queue and when the ball was in my court, they called me to desire my medications. - Non -subscriber, Male, 33 years

A subscriber shared her experienced on the long queue and waiting of time: Most times, the long queues at both the hospital and the NHIS office would discourage you. In fact, it would discourage you from going to seek healthcare. For example, you will wake up early to the NHIS office, only for you to be seated and watch persons who come late, go in and register and you will still be sitting there waiting to be called to.- Subscriber, Female, 31 years

Nonsubscriber shared her experienced on the long queue and waiting of time: As for me, it took me few hours to see a doctor since I was not holding insurance card and so, was not in the long queue. The few hours was terrific for me since those who were holders of (NHIS) card, spent more time over there. For example, there was this woman whom we all walked to the healthcare center when I was leaving, she was still in the queue. - Nonsubscriber Female, 28 years.

\section{Descriptive Statistics of Data of the Regression Model}

This section analyzes statistically the factors that affect the patronage of the NHIS in Ghana in the selected district in Ghana using cross-sectional regression model. The theory highlighting the regression model are tested and the results depicted below.

Table (V). Summary Statistics

\begin{tabular}{lllll}
\hline Units & Mean & Minimum & Maximum & Standard Deviation \\
\hline NHIS & 1.1773 & -0.1922 & 0.3318 & 0.0857 \\
Income Level & 7.0777 & 6.1186 & 8.3279 & 0.4771 \\
Family & & & & \\
Characteristics & 0.7624 & 0.3961 & 0.9834 & 0.1372 \\
Risk Perception & 1.3236 & 0.1697 & 0.2777 & 0.8275 \\
Scheme & & & & \\
Characteristics & 0.7341 & 3.3312 & 4.8121 & 0.5271 \\
Health care System & 1.211 & 0.099 & 1.5614 & 0.8163 \\
\hline
\end{tabular}

From the table $(\mathrm{V})$, it is vivid that, an average of 1.17 is attained by the National Health 
Insurance scheme as the number of subscribers. It comes with a range of 0.139 stems from a minimum of 0.192 for NHA on the number of scribes and a maximum of 0.332 . On the other side, an average of 7.07 of the NHIS was affected by income level based on the findings. In fact, a minimum of 6.118 and maximum 8.327 of NHA experienced income level. On the family characteristics, an average of 0.76 of NHIA did bear family characteristics as a factor with a minimum of 0.396 and a maximum of 0.983 of which NHIA suffered from as factor affecting enrolment. However, Risk perception posted a mean of (1.323), Scheme Characteristics (0.734) and Health care System with a mean (1.211) respectively.

Table (VI). Correlation Coefficient

\begin{tabular}{lllllll}
\hline & NHIS & INCL & FACH & RSPN & SCHA & HCSD \\
\hline NHIS & 1 & & & & & \\
INCL & $-0.1474 * *$ & 1 & & & & \\
FACH & $-0.3651^{* *}$ & 0.4721 & 1 & & & \\
RSPN & $-0.2383^{* *}$ & 0.1293 & 0.0368 & 1 & & \\
SCHA & $0.2383^{* *}$ & 0.5068 & 0.3007 & 0.2202 & 1 & \\
HCSD & $-0.2857^{*} *$ & 0.6498 & 0.5440 & 0.3007 & 0.3436 & 1 \\
\hline
\end{tabular}

The relationship between the variables of the study was tested by correlation. The findings from the table on the correlation depict that, there is a negative relationship between NHIS and the factors variables. (Income level, family characteristics, risk perception, and health care system delivery.) However, there is a positive relationship between NHIS and Scheme Characteristics.

Table (VII). Results of regression of the model (I)

\begin{tabular}{l|l|l|l}
\hline Multiple R & R Square & Adj R-squared & Std. Error of Estimate \\
\hline 0.66 & 0.74 & 0.49 & 3.27 \\
\hline
\end{tabular}

The findings of the table (VII), the independent variables shows about $49 \%$ of the variation in the National Health Insurance Scheme (NHIS). It can be seen that there is a relationship between the variables of the study (Multiple R correlation coefficient), showing 0.66.

Table (VIII). Results of regression model (2)

\begin{tabular}{lllll}
\hline Variables & Coef. & StdErr. & t-stat. & \begin{tabular}{l} 
Palue. \\
\hline
\end{tabular} \\
INCL & -10.72 & 3.59 & $-2.43^{* *}$ & 0.01 \\
FACH & -3.15 & 1.92 & $-1.16^{* *}$ & 0.02 \\
RSPN & -3.37 & 1.77 & $-2.13^{* *}$ & 0.07 \\
SCHA & -2.01 & 3.63 & $-1.81^{* *}$ & 0.01 \\
HSCD & -12.41 & 2.24 & $-3.40^{* *}$ & 0.02 \\
\hline
\end{tabular}

As depicted in the table (VIII), the finding shows that there is a significant negative 
relationship existing between income level, family characteristics, risk perception, scheme characteristics, and health care system delivery and National Health Insurance Scheme. A unit change in income level would lead to a decrease in a number of individuals enrolling into the scheme by 10.72 . However, a unit change in family characteristics, risk perception, scheme characteristics, and health care delivery system would lead to a decrease in individual's enrolment by a margin $(3.15,3.37,2.01,12.41)$ respectively. Therefore, based on the analysis, income level of individual, family characteristics, risk perception, scheme characteristics, and health care delivery system have a significant effect on the patronage of the Ghana health insurance scheme.

Table (IX). ANOVA (Analysis of the Variance)

\begin{tabular}{llllll} 
& $\boldsymbol{d} \boldsymbol{f}$ & $\boldsymbol{S S}$ & $\boldsymbol{M S}$ & $\boldsymbol{F}$ & $\boldsymbol{P r o b}>\boldsymbol{F}$ \\
\hline Model & 4 & 110.523 & 8.7075 & 2.10 & 0.45 \\
Residuals & 1 & 9.535 & 9.50 & & \\
Total & 5 & 120.058 & & & \\
\hline
\end{tabular}

Based on the ANOVA statistics depicted above (table (IX), the independent variables gives a good fit at the significance $\mathrm{F}$ value since is $<0.5$, accordingly the model was statistically significant.

\section{Conclusions}

The study investigated the factors that have accounted for the low patronage of the National Health Insurance Scheme in Ghana. It also seeks to ascertain the factors that motivate individuals to join the scheme and finally examine the challenges of the schemes' coverage expansion. The findings of the results show that majority of the respondents agreed that access to free drugs is the strong arsenal that motivates individuals reluctant joining the scheme. It further reveals that social security against unforeseen health also motivates people to join the scheme. This is consistent with the argument of Mulupi, Kirigia, and Chuma (2014), individuals envisage their subscriptions to health insurance as a way of security in defiance of unforeseen health grievances. Meanwhile, the majority of the participants representing $87 \%$ agreed that the negative attitude of the service providers at the health centers was acknowledged as a major obstacle among both subscriber and non- subscriber in Ghana. This serves as a major obstacle to the subscription and renewal of the scheme. It is continually with a study by Mladovsky and Mossialos (2015).

However, the cross-sectional model was used to investigate the factors accounted for the low enrolment of the health insurances scheme in Ghana in a period spanning from the period of 2015-2018. It was revealed in the study that, Income level, family characteristics, risk perception, and health care system delivery has a significant negative effect on the low enrolment of the national health insurance scheme in Ghana. Therefore, intensive education should be enrolled out by the National Health Insurance Authority (NHIA) to change the 
negative perception of people in relation to the challenges among both subscribers and non-subscribers.

\section{Recommendation and Practical Implications}

The Ghana health insurance scheme was established to ensure improvement in the quality of basic health care services to all citizens. Notwithstanding the seemingly splendid financing structure, yet, there is empirical evidence of low enrolment. The implication of the study is that both subscribers and non-subscribers assessed the motivations and challenges. Subscribers after enrolling on the scheme and exposing enormous barriers, it is likely they would not patronize the scheme. This vividly shows that challenges to subscription supersede the motivation. From the findings of the study, the NHIA should mount rigorous education to transform the perception of citizens regarding the low quality of drugs, and to reduce long queue in accessing healthcare centers and the NHIS offices. Additionally, more rigorous workshop should be systemized by the Ministry of Health, Ghana Health Service and the National Health Insurance Authority (NHIA) to change the negative perceptions of citizens on the factors preventing them to enroll on the scheme as mentioned in the study especially to entreat its employees to display positive and terrific attitudes towards subscribers in exercising their responsibilities in order to inspire non-subscribers to join the scheme.

\section{Funding}

This work was funded by the National Nature Science Foundation of China (71774069).

\section{Acknowledgement}

The authors would like to acknowledge Richard Kofi Mensah, Vivian Bediako, Asumadu Brempong Percy and Halima Antwi Yeboah from the University for Development Studies, Ghana for their enormous contributions towards the study.

\section{References}

Adamba, C. (2011). The Thrills and Tears of national health insurance scheme card holders in Ghana.

Alan C. M., \& Jessica, P. V. (2006). Health insurance enrollment decisions: preferences for coverage, worker sorting, and insurance take up. Working paper 12429.

Appiah, J. C. (2012). House Perceptions and their implications for enrollment in the national health insurance scheme in Ghana. Health policy plan, 2012.

Arhin-Tenkorang, D. (2001). Mobilizing resources for health: the case study for user fees revisited, working paper no.81, Harvard University.

Atim, C., \& Sock, M. (2000). An external evaluation of the Nkoranza Community Financing health insurance scheme, Bethesda: partnership for health reforms.

Carrin, G., Doetinchem, O., Kirigia, J., Mathauer, I., \& Musango, L. (2008). Social health insurance: how feasible is its expansion in the African region? Development issues, 10(2). 
Freeman F, K., \& Zhang, L. (2011). The national health insurance scheme in Ghana: Prospects and challenges: a cross-sectional evidence.

Geng, X., et al. (2018). Health insurance, a friend in need? Impacts of formal insurance and crowding out of informal insurance. World Development, 111, 196-210. https://doi.org/10.1016/j.worlddev.2018.07.004

Grossman, M. (1972). On the concept of health capital and the demand for health. Journal of political economy, 80(2), 223-55. https://doi.org/10.1086/259880

Harmon, C., \& Nolan, B. (2001). Health insurance and health service utilization in Ireland, Health Economics, 10, 135-145. https://doi.org/10.1002/hec.565

He, H., \& Nolen, P. J. (2018). The effect of health insurance reform: Evidence from China. China Economic Review.

He, H., \& Nolen, P. J. (2018). The effect of health insurance reform: Evidence from China. China Economic Review.

James K. K., Remare, E., Catherine, K., Blessing, M., \& Kanyivo, M. (2012), Determinants for participation in public health insurance programme among residents of urban slums in Nairobi, Kenya results from a cross-sectional survey.

Mebratie, A. D., et al. (2015). Enrollment in Ethiopia's Community-Based Health Insurance Scheme. World Development, 74, 58-76. https://doi.org/10.1016/j.worlddev.2015.04.011

Mebratie, A. D., et al. (2015). Enrollment in Ethiopia's Community-Based Health Insurance Scheme. World Development, 74, 58-76. https://doi.org/10.1016/j.worlddev.2015.04.011

Mensah, J., Oppong, J. R., \& Schmidt, C. M. (2010). Ghana's national health insurance scheme in the context of the health MDGs: An empirical evaluation using propensity score matching. Health Economics, 19, 95-106. https://doi.org/10.1002/hec.1633

Mulupi, S., Kirigia, D., Chuma, J., Community perceptions of health insurance and their preferred design features: implications for the design of universal health coverage reforms in Kenya. https://doi.org/10.1186/1472-6963-13-474

National Development planning commission. (2009). 2008 citizens' assessment of the national health insurance scheme of Ghana, towards a sustainable health care financing arrangements that protect the poor. NDPC. Accra.

National health insurance authority. (2015). National health insurance scheme, annual report 2015. Accra.

Nyonator, F., \& Kutzin, J. (1999). Health for some? Effects of user fees in the Volta region of Ghana. Health policy and planning, 14(4), 329-341. https://doi.org/10.1093/heapol/14.4.329

Quaye, R. (1991). Planning the health care system in a decade of economic decline: the Ghanaian experience. Crime, law, and social change. https://doi.org/10.1007/BF00204330 
Ratner, Y., et al. (2018). Patients' satisfaction with hospital health care: identifying indicators for people with severe mental disorder. Psychiatry Research. https://doi.org/10.1016/j.psychres.2018.10.027

Ratner, Y., et al. (2018). Patients' satisfaction with hospital health care: identifying indicators for people with severe mental disorder. Psychiatry Research. https://doi.org/10.1016/j.psychres.2018.10.027

Saltzman, E. (2018). Demand for Health Insurance: Evidence from the California and Washington ACA Exchanges. Journal of Health Economics.

Saltzman, E. (2018). Demand for Health Insurance: Evidence from the California and Washington ACA Exchanges. Journal of Health Economics.

Savage, E., \& Wright, D. (1999). Health insurance and health care utilization: Theory and evidence from Australia 1989-90. Mimeograph. Sydney, University of Sydney.

Singh, P., \& Kumar, V. (2017). Insurance coverage under different health schemes in Uttar Pradesh, India. Clinical Epidemiology and Global Health, 5(1), 33-39. https://doi.org/10.1016/j.cegh.2016.03.002

Singleton, J. L. (2006). Negotiating change: an analysis of the origins of Ghana's national health insurance Act. Department of sociology, Macalester College.

Sulzbach, S., Garshong, B., \& Owusu-Banahene, G. (2005). Evaluating the effects of the national health insurance act in Ghana: Baseline report, Bethesda, MD: partners for health reform project, Abt Associates Inc.

The government of Ghana / SAPRI. (2001). Impact of Structural Adjustment Programme on availability and access to healthcare. Draft, April 2001.

Trujillo, A. J. (2003). Medical care use and selection in social health insurance with an equalization fund: evidence from Colombia, Health Economics, 12(3), 231-246. https://doi.org/10.1002/hec.711

Varatharagan, D., D'almeida, S., \& Kingie, J. (2010 March). Technical brief for policymakers, obstacles in the process of establishing a sustainable NHIS.

Waddington, C., \& Enyimayew, K. A. (1990). A price to pay: the impact of user charges in the Volta region of Ghana. The international journal of health planning and management, 5(4), 150-160. https://doi.org/10.1002/hpm.4740050405

Witter, S., \& Garshong, B. (2009). Something old or something new? Social health insurance in Ghana. BMC international health and human rights, 9(20). [Online] available: http://www.biomedcentral.com/147-698X/9/20.

Xu, K., Evans, D., Carrin, G., Aguilar-Rivera, A. M., Musgrove, P., \& Evans, T. (2007). Protecting households from catastrophic health spending. Health Affairs (Millwood), 26, 972-983. https://doi.org/10.1377/hlthaff.26.4.972 
Appendix 1

\section{Selected Districts for the Study.}

1. Kwabre East.

2. Afigya kwabre.

3. Offinso North.

4. Afigya Sekyere South.

5. Ejura-Sekyeredumase.

\section{Copyright Disclaimer}

Copyright for this article is retained by the author(s), with first publication rights granted to the journal.

This is an open-access article distributed under the terms and conditions of the Creative Commons Attribution license (http://creativecommons.org/licenses/by/4.0/). 